Document downloaded from:

http://hdl.handle.net/10251/64715

This paper must be cited as:

Serrano Cruz, JR.; Olmeda González, PC.; Arnau Martínez, FJ.; Reyes Belmonte, MA.; Tartoussi, H. (2015). A study on the internal convection in small turbochargers. Proposal of heat transfer convective coefficients. Applied Thermal Engineering. 89:587-599. doi:10.1016/j.applthermaleng.2015.06.053.

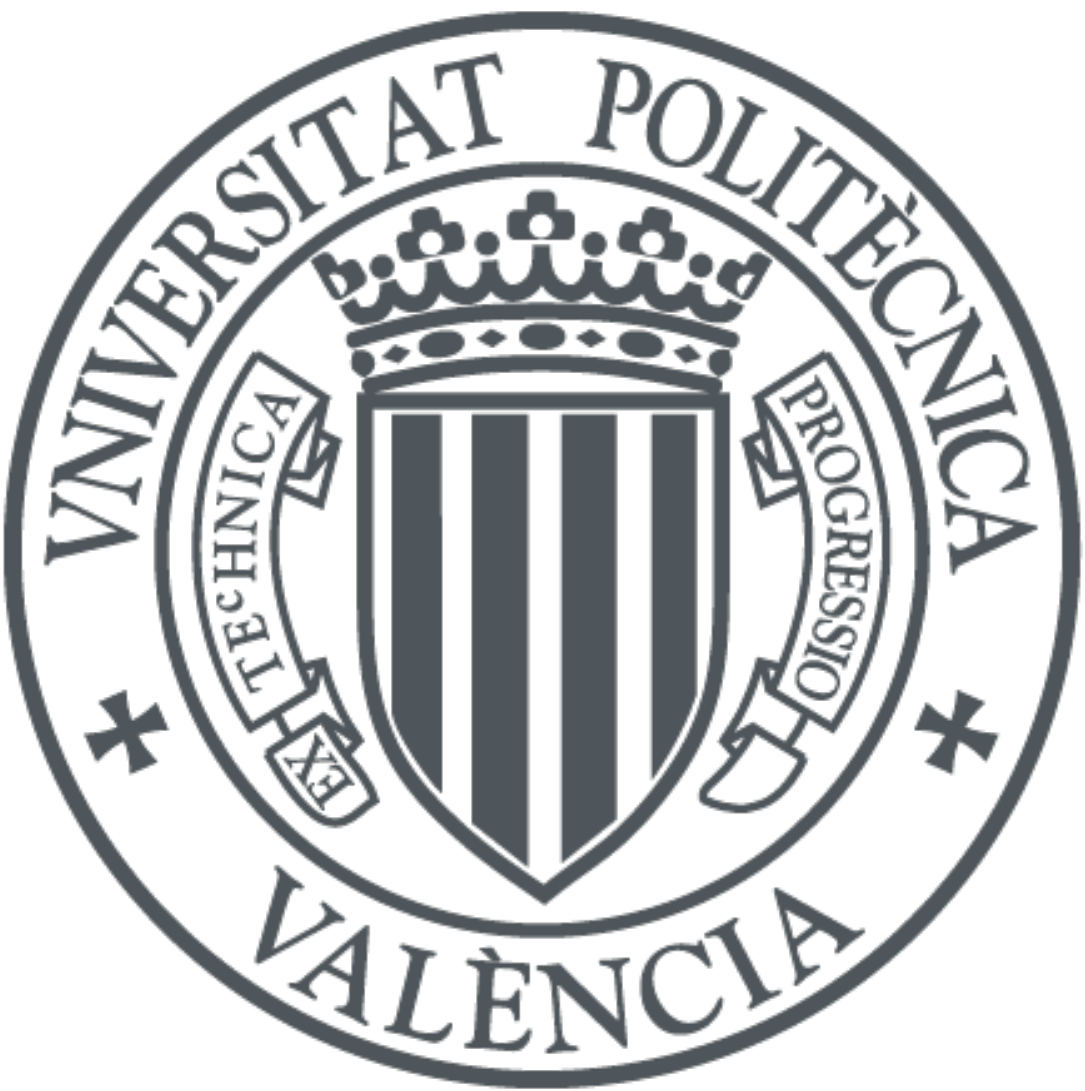

The final publication is available at

http://dx.doi.org/10.1016/j.applthermaleng.2015.06.053

Copyright Elsevier

Additional Information 


\title{
A study on the internal convection in small turbochargers. Proposal of heat transfer convective coefficients
}

\author{
José R. Serrano, Pablo Olmeda*, Francisco J. Arnau, Miguel A. \\ Reyes-Belmonte \\ CMT-Motores Térmicos, Universitat Politècnica de València, Camino de Vera s/n. 46022 \\ València, Spain \\ Hadi Tartoussi \\ Renault S.A.S., Powertrain Division, Centre Technique de Lardy, France
}

\begin{abstract}
Nowadays turbochargers play an important role in improving internal combustion engines (ICE) performance. Usually, engine manufacturers use computer codes to predict the behaviour of both engine and turbocharger, the later by means of measured look-up maps. Using look-up maps different problems arise, being one of the most important the difference in heat transfer between the current operating condition and the conditions at which maps were measured. These effects are very important at low to medium turbocharger speeds (typical condition of urban driving conditions) where heat transfer can even be higher than mechanical power. In this work, the different convective heat transfer phenomena inside these kind of machines have been measured and analysed. Besides, general correlations for these flows, based on dimensionless numbers, are fitted and validated in three different turbochargers. The applicability of the model is shown by comparison the main results obtained when the model is used and not, improving up to $20{ }^{\circ} \mathrm{C}$ the predicted turbine outlet temperature. The main advantages of applying these correlations rely on predicting fluids outlet
\end{abstract}

\footnotetext{
${ }^{*}$ Corresponding author. Tel: +34963877650 ; fax: +34963877659

Email address: pabolgon@mot.upv.es (Pablo Olmeda)

$U R L$ : www.cmt.upv.es (Pablo Olmeda)
}

Preprint submitted to Elsevier

July 14, 2015 
temperatures (compressor, turbine, oil and coolant). The former is needed to feed accurately ICE model, turbine outlet temperature is important for aftertreatment device modelling while oil and coolant temperatures are important in order to design optimum cooling systems.

Keywords: Turbocharger, Heat transfer, Convective coefficients, experimental analysis

\section{Nomenclature}

\begin{tabular}{|c|c|c|}
\hline$A$ & Area & $\mathrm{m}^{2}$ \\
\hline$c$ & Specific heat capacity & $\mathrm{J} \cdot \mathrm{kg}^{-1} \cdot \mathrm{K}^{-1}$ \\
\hline$C$ & Capacitance, capacitance matrix & $\mathrm{J} \cdot \mathrm{K}^{-1}$ \\
\hline$D$ & Diameter & $\mathrm{m}$ \\
\hline$h$ & Convective coefficient & $\mathrm{W} \cdot \mathrm{m}^{-2} \cdot \mathrm{K}^{-1}$ \\
\hline$H$ & Convective heat vector & $\mathrm{W} \cdot \mathrm{m}^{-2} \cdot \mathrm{K}^{-1}$ \\
\hline$\dot{H}$ & Enthalpy flow & $\mathrm{W}$ \\
\hline$I$ & Identity matrix & - \\
\hline$K$ & Conductance, conductance matrix & $\mathrm{W} \cdot \mathrm{K}^{-1}$ \\
\hline$L$ & Length & $\mathrm{m}$ \\
\hline$m$ & Mass & $\mathrm{kg}$ \\
\hline$\dot{m}$ & Mass flow & $\mathrm{kg} \cdot \mathrm{s}^{-1}$ \\
\hline$N$ & Power & $\mathrm{W}$ \\
\hline $\mathrm{Nu}$ & Nusselt number & - \\
\hline$p$ & Pressure & $\mathrm{Pa}$ \\
\hline $\operatorname{Pr}$ & Prandtl number & - \\
\hline$q$ & Heat flow & $\mathrm{W}$ \\
\hline$Q$ & Heat vector & $\mathrm{W}$ \\
\hline$\dot{Q}$ & Heat flow & $\mathrm{W}$ \\
\hline$R$ & Radius & $\mathrm{m}$ \\
\hline $\operatorname{Re}$ & Reynolds number & - \\
\hline
\end{tabular}




\begin{tabular}{|c|c|c|}
\hline$T$ & Temperature & $\mathrm{K}$ \\
\hline$\dot{W}$ & Power & $\mathrm{W}$ \\
\hline \multicolumn{3}{|c|}{ Greeks symbols } \\
\hline$\eta$ & Efficiency & - \\
\hline$\pi$ & Pressure ratio & - \\
\hline$\mu$ & Dynamic viscosity & $\mathrm{Pa} \cdot \mathrm{s}$ \\
\hline$\nu$ & Kinematic viscosity & $\mathrm{m}^{2} \cdot \mathrm{s}^{-1}$ \\
\hline$\rho$ & Density & $\mathrm{kg} \cdot \mathrm{m}^{-3}$ \\
\hline$\kappa$ & Conductivity & $\mathrm{W} \cdot \mathrm{m}^{-1} \cdot \mathrm{K}^{-1}$ \\
\hline$\theta$ & Dimensionless temperature & - \\
\hline \multicolumn{3}{|c|}{ Subscripts and superscripts } \\
\hline$A$ & Refers to fluid passing through compressor & \\
\hline$b c$ & Boundary conditions & \\
\hline$c$ & Compression & \\
\hline$C$ & Compressor node & \\
\hline$C O D$ & Compressor outlet duct & \\
\hline$O C$ & Compressor outlet temperature & \\
\hline$I C$ & Compressor inlet temperature & \\
\hline Air & Diffuser outlet temperature & \\
\hline$e$ & Expansion & \\
\hline eff & Effective & \\
\hline Gas & Refers to fluid passing through turbine & \\
\hline$H 1$ & Housing node (turbine side) & \\
\hline$H 2$ & Housing node (central side) & \\
\hline$H 3$ & Housing node (compressor side) & \\
\hline$i, j, k, l$ & General component & \\
\hline$O$ & Refers to oil or outlet & \\
\hline$p$ & Turbine inlet port & \\
\hline$T$ & Turbine node & \\
\hline$v$ & Turbine volute & \\
\hline
\end{tabular}




\section{VGT Variable Geometry Turbocharger \\ $W \quad$ Refers to coolant fluid}

\section{Introduction}

Nowadays the main challenges in internal combustion engines (ICE) consist on the reduction of fuel consumption and pollutant emissions. With this purpose different techniques have appeared to optimize the combustion process: high pressure fuel injection systems [1], multiple injections [2, high boost pressure [3, two stage turbocharging [4], EGR [5], variable valve timing [6], high swirl ratios [7, new clean fuels [8, etc. In this framework, the optimization of engine external systems can play an important role, one of these systems is the turbocharger. In order to predict accurately engine behaviour it is necessary to predict turbocharger behaviour, since, among others, it will affect the intake air temperature which highly affect combustion process and therefore engine performance [9] and the exhaust temperature which highly affects pollutant emissions [10. This behaviour must bear in mind at least three main factors: isentropic efficiency of the turbomachinery, mechanical power effectively transferred from the turbine to the compressor through the central axis [11 and the heat fluxes between turbine and compressor side due to differences in working fluids temperatures. This work falls in the third item, contributing to the knowledge of the internal convention phenomena in turbochargers. Traditionally, turbochargers behaviour has been considered as an adiabatic process due to the high velocity of the working fluids. This approach leads to important errors in turbocharger prediction for low speeds, typical during urban driving conditions.

Bohn studied heat transfer in a turbochargers by means of experimental 12] and three dimensional modelling [13] in order to obtain a heat transfer correlation for the compressor side. It was showed that at low speed, heat transfer flows from turbine to compressor while at high speed, heat transfer flows from compressor to lubricating oil. That is due to the higher mean temperature of the air in the compressor outlet. 
Consequences of considering adiabatic conditions in the compressor generally leads to underestimate (if heat flows from compressor to lube oil) or overestimates (if heat flows in the opposite way, i.e. form turbine to compressor) isentropic efficiency using measured inlet and outlet temperatures [14]. On the contrary, same errors are committed estimating compressor outlet temperatures if efficiency provided by manufactures maps are used [15. If turbine is considered as adiabatic, non-considered heat fluxes effects will lead to an overestimation of turbine isentropic efficiency. Since, during normal operation conditions, heat flows from turbine to lube oil, for many conditions, turbine isentropic efficiency (evaluated with measured temperatures) can provide higher values than reality, even higher than one [16]. For that reason, it is a common practice giving turbocharger efficiency as the ratio between compressor absorbed power and turbine isentropic power [17]).

Turbocharger heat transfer studies are quite recent, for example Baines [16] fitted forced convection correlations in order to satisfy the energy balance in all the measured points. It was assumed that errors or uncertainties in measured parameters were subsumed into the convective heat transfer coefficients and correlations. Cormerais [18] optimized thermal resistances fitting the experimental data but convective heat transfer was obtained in an indirect way, since the form of correlations had been previously imposed. Cheesé et al. [19] obtained heat transfer to the compressor by comparing tests at hot and cold conditions. They assumed heat transfer in the compressor side occurred after the impeller, in the diffuser and volute, contrary to other authors [9] since constant speed lines were not modified when turbine inlet temperature was changed. Cheesé [19] also assumed that mechanical power absorbed by the impeller was not affected by heat transfer, since it was constant, whatever was turbine inlet temperature. Main problem of that approach was the range of the measured regions: the higher the turbine inlet temperature was, the larger the measured zone was and, therefore, comparison on all points was not possible.

Romagnoli [20] assumed a Dittus-Boelter [21] correlation for compressor heat transfer but direct measurements were not shown. Aghaali 22] used multipli- 
ers in order to fit a GT-Power model to the measurements, but no convective correlations were given. Burke [23] used different correlations to estimate the performance of a turbocharger on an engine test bench. Lavagnoli [24] studied different approaches to estimate the relevant flow parameters that drive the heat transfer based on transient turbine experiments but not the whole heat flows between turbine and compressor were studied.

In this work a concise methodology to obtain heat transfer correlations by measuring heat fluxes between the different turbocharger elements has been presented. First part of this paper concerns about the experimental methodology and main parameters measured to characterize internal heat transfer. Later turbocharger physical model is presented. After that, results are presented and, finally, main conclusions are outlined.

\section{Test rig description}

Figure 1 shows the layout of a continuous air flow test bench [1]. It is composed by the following devices:

- A screw compressor with a maximum mass flow capacity of $0.2 \mathrm{~kg} \cdot \mathrm{s}^{-1}$, at a maximum discharging pressure of 3.5 bar (gauge), which provides the mass flow to the turbine. Mass flow rate is controlled by changing the screw compressor speed or the opening of an electronic discharge valve (placed downstream the screw compressor). This valve is used when a lower mass flow than the minimum supplied by the screw compressor is required being discharged to the atmosphere the extra flow.

- Mass flow is heated in parallel using five tube-type electrical heaters, mass flow through each of the heaters can be regulated by means of a valve placed at their inlet ports. This system can reach up to $720 \mathrm{~K}$ at the maximum mass flow rate, this hot flow is collected later in a plenum and conducted to the turbine inlet. 
- After passing through the turbine, the air is cooled by means of a heat exchanger in order to allow mass flow measurement using high accuracy hot film flow meter. All flow meters in the installation have been previously calibrated.

- Turbo-compressor sucks air from the atmosphere, air passes first through a filter before being measured. Downstream the compressor, an electronically driven back-pressure valve has been installed in order to emulate what would be engine intake valves. Hereinafter compressor refers only to the turbo-compressor.

- An independent lubrication system is installed to control oil flow rate and its inlet pressure (by means of an oil pump and a controlled pressure valve). Temperature can be also controlled and modified as desired by using an electrical heater and a cooler. Oil mass flow rate is measured by means of a Coriolis flow meter, meanwhile inlet and outlet temperatures are measured using platinum resistance temperature detectors. Oil samples are taken periodically in order to characterize its properties (viscosity, density and specific heat capacity variations with temperature).

- Temperature and pressure sensors are installed on the inlet and the outlet pipes of the compressor and the turbine according to SAE (Society of Automotive Engineers)) J1723 [25] and SAE J1826 [26] standards. In this way the obtained results would be applied very quickly on any turbocharger previously measured following these standards that is usually performed in industry. This fact will be very interesting for both engine and turbocharger manufacturers. The methodology employed and the obtained results in this work could be used in other turbochargers previously tested following these standards which give an interesting and non-negligible tool for both researchers and industry.

Table 1 shows main information about measurement range and uncertainty of sensors used in the test bench. Tests performed on this flow rig have been 


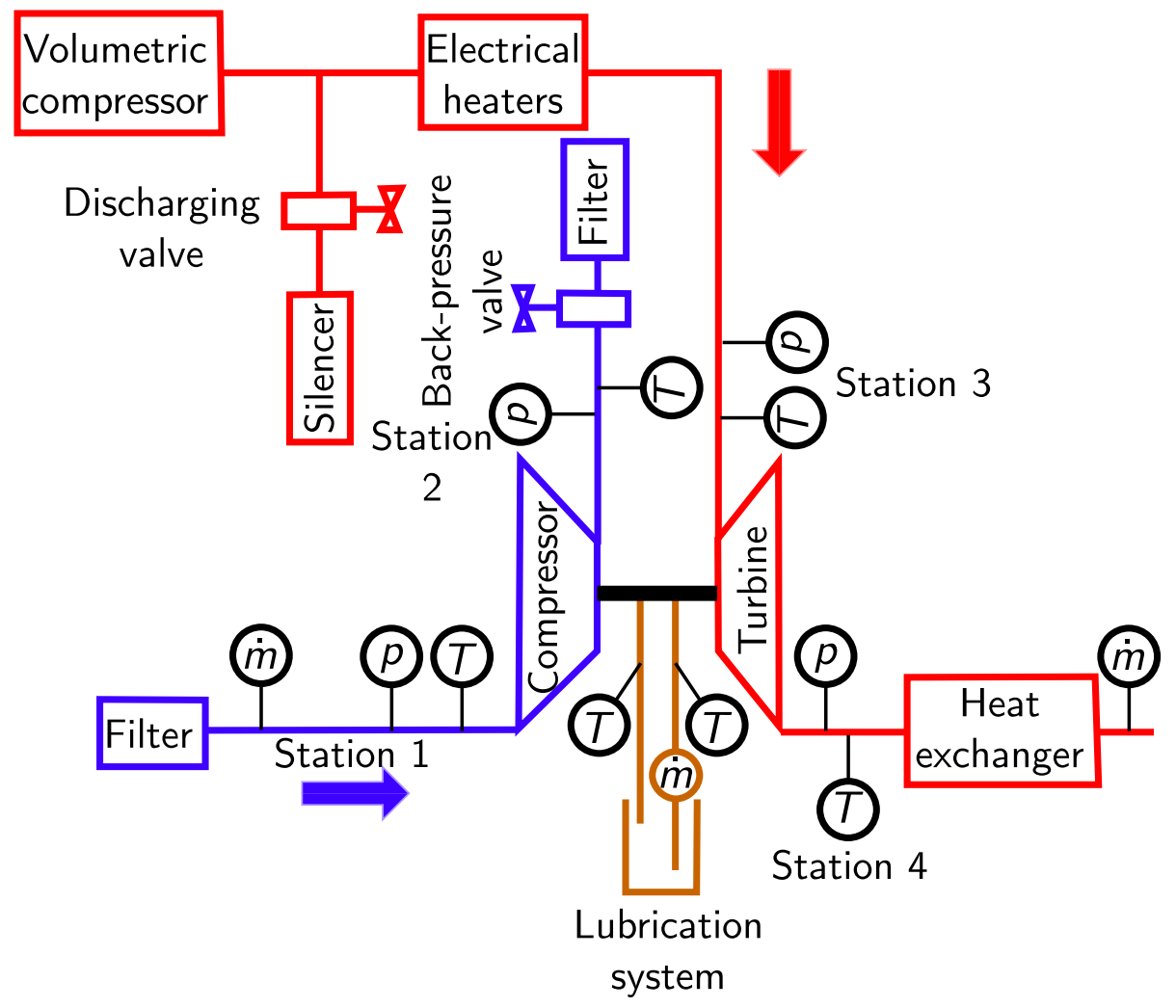

Figure 1: Schematic test bench and location of main sensors. 
divided into two main groups, named as:

1. Almost-adiabatic tests $[9$. Whose main objective is to decouple mechanical losses characterization from heat transfer problem in the turbocharger under study 27. In this way, heat transfer is minimized by setting turbine inlet, compressor outlet and lubricating oil inlet temperatures at the same level. Doing so lubricating oil enthalpy drop corresponds to the direct measurement of turbocharger mechanical losses that will be characterized and modelled using an empirical [28] or a physical model [11.

2. Hot tests [10]. Main objective of this kind of tests is to characterize convective heat fluxes inside the turbocharger. Besides, these tests can be divided into two main groups:

(a) Externally insulated tests. In these tests the whole turbocharger is externally insulated avoiding heat fluxes to the environment, appearing only internal heat fluxes.

(b) Exposed tests. These tests are the usually performed by manufacturers in order to obtain turbocharger maps. Main difference respect to previous tests comes from the fact that heat fluxes to the environment are allowed. Environment conditions (temperature) and air flow through the bench have been measured in order to estimate accurately these heat fluxes.

In this work, externally insulated tests have been performed in order to obtain, internal convective coefficients and correlations. These internal heat transfer fluxes have been obtained according to the thermal model explained in section 3

In order to extend validity of this work, three different turbochargers have been studied, whose main characteristics are shown in Table 2. Performance maps from those turbochargers are observed in Figure 2. These turbochargers are typical used in small-medium Diesel engines, so the obtained results could be applied to similar turbochargers, i.e. similar sizes and compression/expansion 
Table 1: Characteristics of sensors employed in the test bench

\begin{tabular}{lll}
\hline Variable & Sensor & Range / Error \\
\hline Gas Pressure & Piezoresistive & {$[0-5] \pm 0.025 \mathrm{bar}$} \\
Air Pressure & Piezoresistive & {$[0-2] \pm 0.025 \mathrm{bar}$} \\
Gas and Air Temp. & K-type Therm. & $-200-+1200 \pm 2.2^{\circ} \mathrm{C}$ \\
Gas and Air Flow & Hot wire & {$[0-720] \pm 0.72 \mathrm{~kg} / \mathrm{h}$} \\
\hline Oil Pressure & Piezoresistive & {$[0-6] \pm 0.025 \mathrm{bar}$} \\
Oil Temperature & RTD & {$[-200-+650] \pm 0.15{ }^{\circ} \mathrm{C}$} \\
Oil Flow & Coriolis & {$[0-100] \mathrm{kgs}^{-1} \pm 0.1 \%$} \\
\hline
\end{tabular}

ratios. The knowledge of heat transfer in this engines could lead to an improvement of their performance by reducing energy losses.

Table 2: Main characteristics of the employed turbochargers

\begin{tabular}{cccc}
\hline Parameter & $\begin{array}{c}\text { First } \\
\text { turbocharger }\end{array}$ & $\begin{array}{c}\text { Second } \\
\text { turbocharger }\end{array}$ & $\begin{array}{c}\text { Third } \\
\text { turbocharger }\end{array}$ \\
\hline Turbine wheel diameter $[\mathrm{mm}]$ & 41 & 38 & 36.5 \\
Compressor wheel diameter $[\mathrm{mm}]$ & 49 & 46 & 40 \\
VGT & yes, vanes & yes, vanes & no \\
Water cooled & yes & no & yes \\
Type of journal bearing & fixed & floating ring & floating ring \\
Engine power $[\mathrm{kW}]$ & 129 & 96 & 75 \\
Engine type & diesel & diesel & petrol \\
Displacement $[1]$ & 2.0 & 1.6 & 1.2 \\
\hline
\end{tabular}

\subsection{Uncertainty analysis}

The uncertainty of a measurement is a parameter that characterises the dispersion of the values that could reasonably be attributed to the action of 

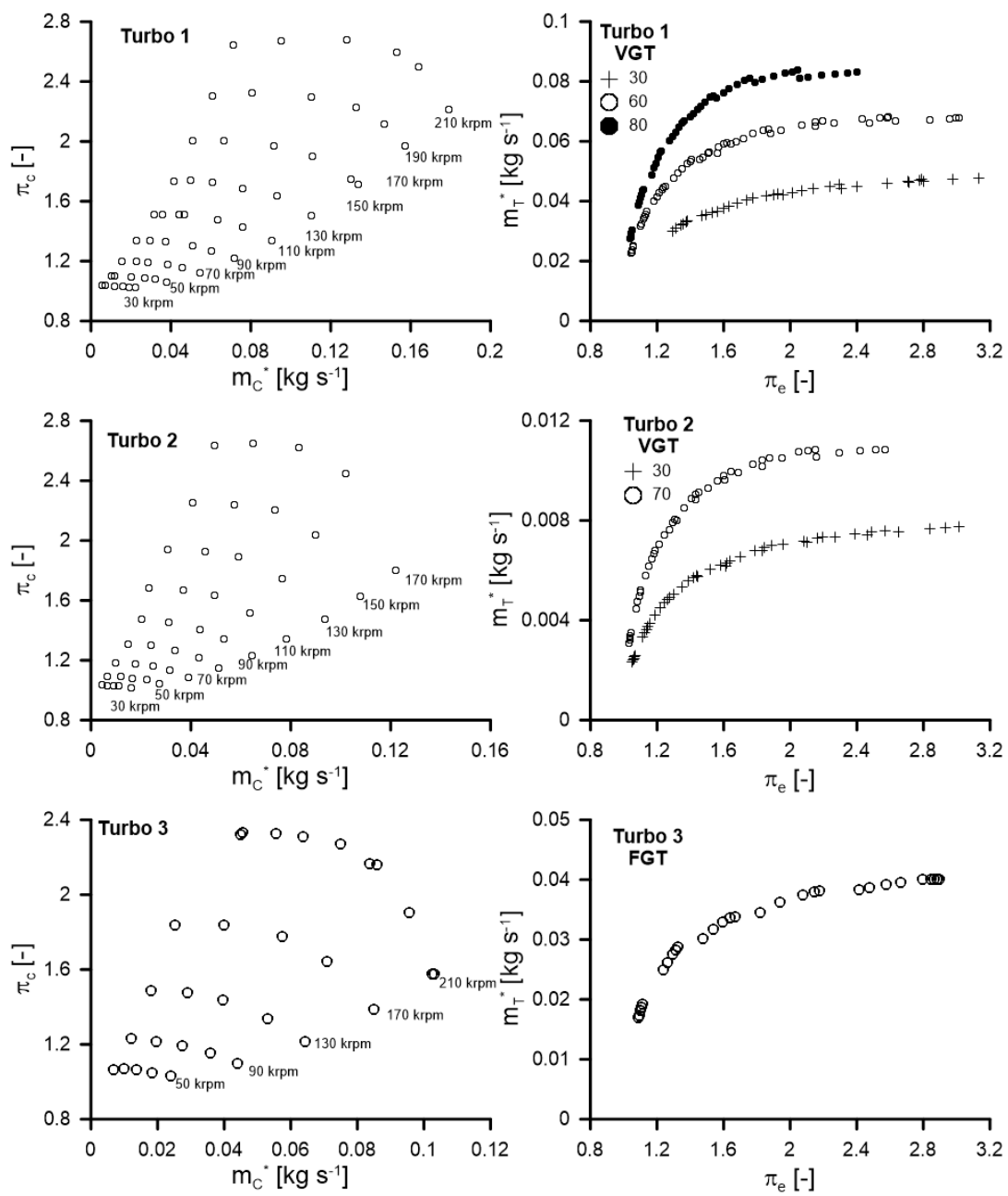

Figure 2: Measured points for convective characterization. Left side compressor maps and right side turbine maps. Legends refer to VGT opening in \% 
measuring. As it has been proposed in [29] the uncertainty estimation can be evaluated by using a statistical analysis of series of observations and by other means, such as manufacturers data. In the case of the measurements of current work both types of evaluations have been performed. In one hand, the standard deviation due to the repetitiveness of the measurement is calculated using Equation 1 , where $n$ is the number of measurements, $\bar{x}$ is the arithmetical mean of these measurements and $x_{i}$ the measurement. On the other hand the standard deviation due to the inaccuracy of each sensor can be computed using manufacturer data on the probability distribution of the error or assuming uniform rectangular distribution of probability if only the bounds are given [29]. In this last case the standard deviation is calculated using Equation 2 from uniform rectangular distribution of probability, where $a_{-}$and $a_{+}$are the lower and the upper limits of the sensor inaccuracy.

$$
\begin{aligned}
& u_{a}=\sqrt{\frac{\sum_{i=1}^{n}\left(x_{i}-\bar{x}\right)^{2}}{n-1}} \\
& u_{b}=\sqrt{\frac{\left(a_{+}-a_{-}\right)^{2}}{12}}
\end{aligned}
$$

Finally the standard deviation, representing combined uncertainty is calculated using Equation 3, taking into account both of the previous effects. Furthermore, it is also used for the computation of the uncertainty of derived variables. Using these expression all the measured or computed variables of this paper are provided with uncertainty limits given in terms of standard deviation. Uncertainty in fluid temperatures, wall temperatures and mass flows measurements are shown in Table 1, which combined with Equation 3, yield a maximum uncertainty in heat transfer measurements of $8 \%$ of the measured magnitude.

$$
u_{c}=\sqrt{\sum_{i=1}^{k}\left(\frac{\partial f}{\partial x_{i}}\right)^{2} \cdot u^{2}\left(x_{i}\right)}
$$




\section{Turbocharger thermal model}

A lump capacitance model of the turbocharger is proposed. In this kind of models, the turbocharger is considered as a thermal network consisting in a finite number of nodes, whose thermal inertia is characterized by a thermal capacitance, and linked with other nodes by means of thermal conductances. These models assume a uniform temperature on each of the nodes, so discrimination must bear this fact into account. The higher the model discretization and the consideration of more complex approaches (as contact resistances) [30, the more accuracy can be obtained [31, but on the contrary, higher number of parameters must be determined or fitted. The practical use of this kind of models regards on a compromise between accuracy and the number of fitted parameters. Once model structure has been divided into several nodes, energy conservation equation can be written for each node, i.e. the sum of heat fluxes between nodes, convective heat fluxes and other heat fluxes in a time interval equals the change in sensible energy of the node:

$$
\begin{array}{r}
m_{i} \cdot c_{v} \frac{T_{t+\Delta t}^{i}-T_{t}^{i}}{d t}= \\
=\sum_{j} K_{i j}\left(T_{t+\Delta t}^{j}-T_{t+\Delta t}^{i}\right)+\sum_{k} q_{k \rightarrow i}+\sum_{l} h_{l i} A_{l i}\left(T_{t+\Delta t}^{l}-T_{t+\Delta t}^{i}\right)
\end{array}
$$

Writing Equation 4 for each of the $n$ nodes gives a set of linear, implicit equations of the form:

$$
\left(K+\frac{1}{\Delta t} C\right) T_{t+\Delta t}=Q+\frac{1}{\Delta t} C T_{t}+H
$$

In steady-state conditions $(t=t+\Delta t)$, Equation 5 reduces to

$$
K T=Q+H
$$

If boundary conditions are added to Equation 6 as temperatures, $T_{b c}$, Equation 7 can be obtained:

$$
\left(\begin{array}{cc}
I & 0 \\
H & K
\end{array}\right)\left(\begin{array}{c}
T_{b c} \\
T_{\text {unknown }}
\end{array}\right)=\left(\begin{array}{c}
T_{b c} \\
0
\end{array}\right)
$$


Nodes numbers and their positions have been selected attending to turbochargers geometry and previous studies [32]. Discrimination used in this work (Figure 3(b) consists on a thermal resistor network with five solid nodes (one for the Turbine housing, three for the central bearing housing and a last one for the compressor housing).
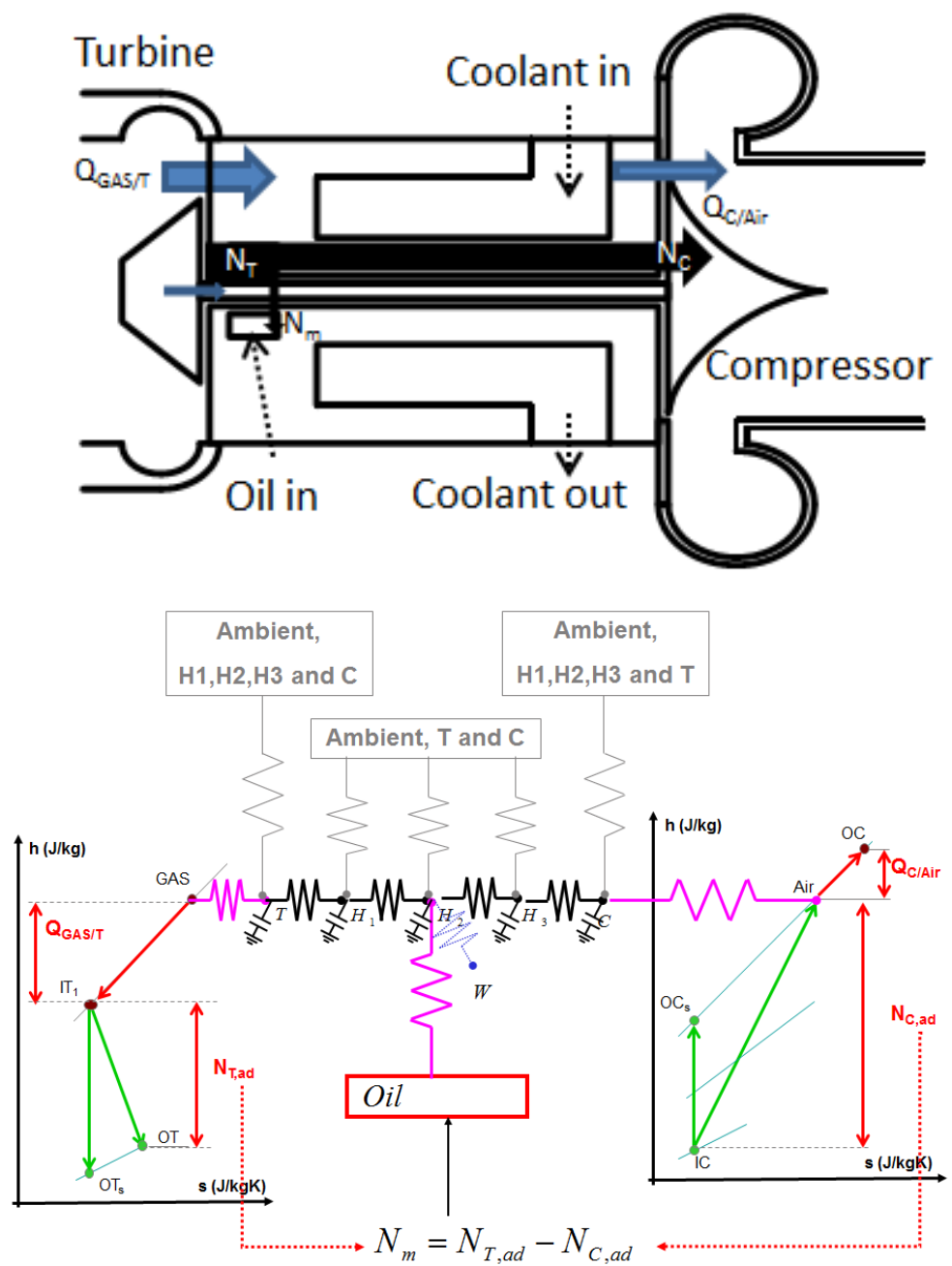

Figure 3: Main energy flows in a turbocharger and the lumped model for the turbochargers 
As mentioned, one of the objectives of this work is to provide a simple, accurate enough and a fast tool to predict heat fluxes on turbochargers. This tool should be flexible enough to be applied with the known characteristics of the turbocharger, i.e.: external dimensions and material of casings. This reason lead to choose only five nodes since a higher discrimination, taking into account rotating parts as turbine or compressor wheels, would imply a higher number of parameters to be demand to the final user. Besides the heat fluxes through the shaft is very low compared to total energy flux through the element [33]. Nevertheless, a more detailed lumped model can be simplified to a simple one if conductances are considered constants and taking into account the type of connections among the nodes (in-line or in parallel) 34 .

Boundary conditions are represented by five convective nodes (turbine gases, lube oil, compressor air, ambient and cooling fluid) in the case of turbochargers with cooling media. These nodes are characterized by their average temperatures and film coefficients. Conductive characteristics were previously obtained on a specific test bench following the methodology described by Serrano et al. 32. Therefore after conductive characterization the whole turbocharger behaves as a heat flux sensor, i.e. heat fluxes can be estimated directly from wall temperatures without any extra instrumentation. This characterization procedure is the first step for analysing any turbocharger but if there is no possibility to obtain experimentally these conductances, the use of a generic correlation could be used [35]. The whole procedure for characterize completely a turbocharger is explained on [36.

\section{Results Analysis}

The different convective coefficients $\left(h_{G a s / T}, h_{C / A i r}, h_{H 2 / W}\right.$ and $\left.h_{H 2 / O i l}\right)$ can be obtained using a combination of Fouriers law of heat conduction and Newtons law of cooling [37]:

$$
h_{i, j}=\frac{K_{j, l} \cdot\left(T_{j}-T_{l}\right)}{A_{i, j} \cdot\left(T_{i}-T_{j}\right)}
$$


where $i$ represents a convective node; $j$ and $l$ denote conductive nodes; $K_{j, l}$ represents the conductance between conductive nodes; $A_{i, j}$ is the contact area between fluid and wall and $T$ is the temperature of the node. Once the convective coefficient is determined, a correlation between dimensionless numbers (Nusselt and Reynolds mainly) can be looked for.

\subsection{Turbine heat transfer coefficient}

As mentioned in section 4 , convective heat flux in the turbine side $\left(\dot{Q}_{G a s / T}\right)$ is equal to conductive heat flux $\dot{Q}_{T / H 1}$ according to the lumped model shown in Figure $3(\mathrm{~b})$, where no heat losses to the ambient are allowed since the turbocharger was fully insulated during the tests. Therefore, this heat flux can be obtained directly from measured temperatures in nodes $T$ and $H 1$ and the previously determined conductive conductance between these two nodes. The way those conductances were obtained can be found in 32 .

$$
\dot{Q}_{G a s / T}=\dot{Q}_{T / H 1}=K_{T / H 1} \cdot\left(T_{T}-T_{H 1}\right)
$$

Figure 4 shows this heat flux $\left(\dot{Q}_{G a s / T}\right)$ versus the enthalpy drop in the turbine, in addition its relative importance compared to the enthalpy flow drop across the turbine has also been shown. In this way the importance of heat fluxes on turbine side are determined and this fact gives information about where the heat flux studies must be focused, i.e. the higher the relative importance is, the more accuracy should be looked for. Figure 4 shows that the higher the enthalpy flow drop in the turbine $\left(N_{t}=\Delta \dot{H}_{T}\right)$ is, the higher the heat flux is. Until a kind of stabilization or small reduction, on $\dot{Q}_{G a s / T}$ is observed at high $N_{t}$, probably due to a lower residence time as a consequence of higher flow velocities. Nevertheless, if that heat is compared to the total enthalpy drop across the turbine, its relative importance at high $N_{t}$ becomes lower than $5 \%$ of the total energy. However, heat transfer effects from operative points corresponding to low loads conditions (low $N_{t}$ ) are quite considerable (almost the whole total enthalpy drop in some cases). This fact indicates the need to 
predict more accurate heat fluxes at low load condition than at higher loads, where turbine enthalpy drop consists almost exclusively on mechanical power.
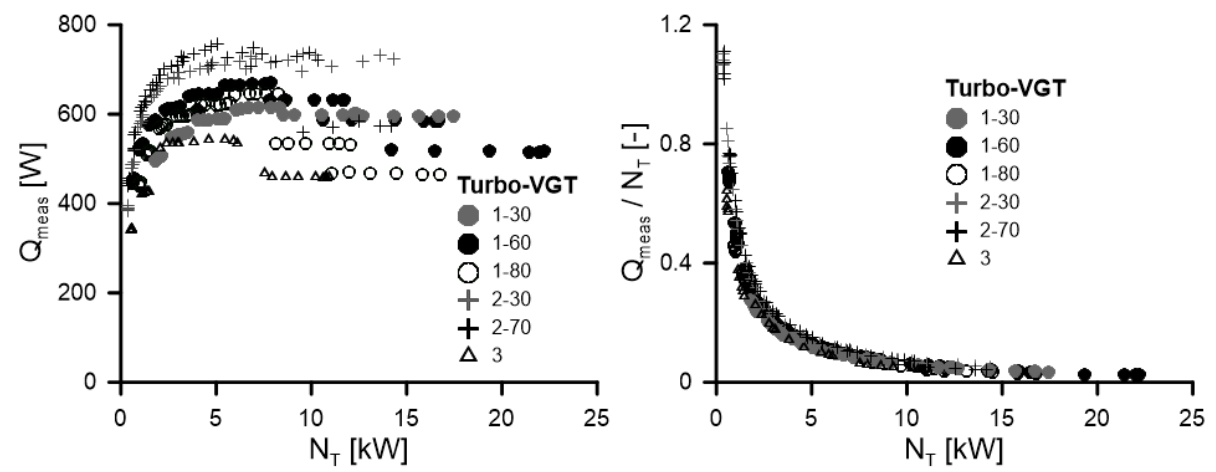

Figure 4: Importance of heat flux $\dot{Q}_{G A S / T}$. Left: absolute value, Right: relative importance compared to turbine enthalpy drop. Legends refer to turbocharger number and VGT opening in $\%$

Turbine heat transfer losses are assumed to take place at turbine inlet, i.e. the processes followed by gases are: first a heat transfer exchange and later a polytropic expansion in the turbine, as shown in Figure 3(b) and as other authors have also proposed [16. The convective correlation of this heat flux has been performed by dimensionless numbers:

$$
\begin{gathered}
\operatorname{Re}_{m T}=\frac{4 \cdot \dot{m}}{\pi \cdot \mu \cdot D_{\text {eff }}} \\
\overline{\mathrm{Nu}_{G a s / T}}=\frac{h \cdot D_{e f f}}{\kappa}=\frac{\dot{Q}_{G a s / T}}{A \cdot\left(T_{G A S}-T_{T}\right)} \cdot \frac{D_{e f f}}{\kappa}= \\
=\frac{K_{T / H 1} \cdot\left(T_{T}-T_{H 1}\right)}{\pi \cdot D_{e f f} \cdot L_{e f f} \cdot\left(T_{G A S}-T_{T}\right)} \cdot \frac{D_{e f f}}{\kappa}=\frac{K_{T / H 1} \cdot\left(T_{T}-T_{H 1}\right)}{\pi \cdot \kappa \cdot L_{e f f} \cdot\left(T_{G A S}-T_{T}\right)}
\end{gathered}
$$

Where the length scale for Reynolds number is $D_{\text {eff }}=D_{p} ; D_{p}$ denotes turbine inlet port diameter which gives a good estimation of average Reynolds number through turbine [38] and $L_{e f f}=\frac{D_{v}^{2}}{4 \cdot D_{p}}$ where $D_{v}$ represents turbine volute diameter, i.e. the contact area between gas and turbine node can be represented by the whole turbine frontal area (since heat transfer during expansion process can be neglected without affecting the results [39]) and in order to 
simplify the problem, air properties (conductivity, density, viscosity and heat capacity) and their small variation for the considered temperature ranges, have been calculated at turbine inlet temperature. Doing so, Nusselt numbers have been calculated for each measured point observing a clear trend with Reynolds number as Figure 5 shows. In addition, due to the rotor-stator wakes interaction, which is the most important mechanism in observed flow distortion through rotor blades by 40, and later on confirmed by 41] a kind of correction must be employed. These flow interaction is clearly determined by the position of the stator blades in the Variable Geometry Turbocharger (VGT) [42.

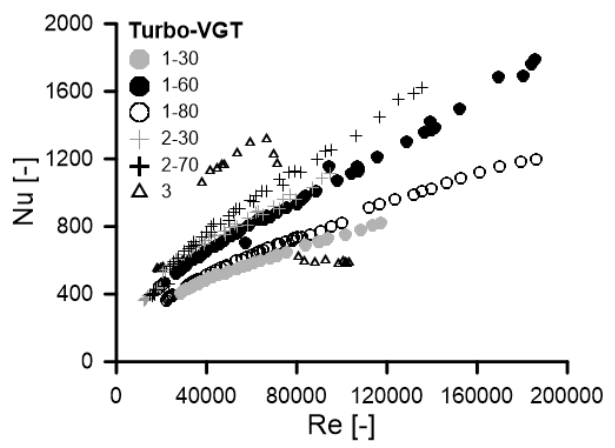

Figure 5: Nusselt number versus Reynolds number from convection in Gas/T. Legends refer to turbocharger number and VGT opening in \%

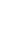

effect of VGT opening on flow distortion as Equation 12 shows

$$
\overline{\mathrm{Nu}_{G a s / T}}=a \cdot \operatorname{Re}_{m T}^{b} \cdot \operatorname{Pr}^{1 / 3} \cdot\left(\frac{\mu}{\mu_{w}}\right)^{0.14} \cdot \Psi
$$

Figure 6 shows both the modeled Nusselt number and heat fluxes from node Gas to metal node $T$ versus the measured ones. Boundary lines in 6(b) shows $\pm 20 \%$ error. A fitting procedure, minimizing the root mean square of errors using SLSQP algorithm developed by Kraft [43] has been used. Equation 13 shows obtained values for constants and best correlation for $\Psi$ parameter. 


$$
\overline{\mathrm{Nu}_{G a s / T}}=1.29 \cdot \operatorname{Re}_{m T}^{0.52} \cdot \operatorname{Pr}^{1 / 3} \cdot\left(\frac{\mu}{\mu_{w}}\right)^{0.14} \cdot \eta_{V G T, \max }^{-3.72}
$$

Where $\eta_{V G T, \max }$ represents the maximum turbine isentropic efficiency of the corresponding VGT opening (determined from adiabatic measurements or an extrapolation procedure as the one used in [44]). The $\eta_{V G T, \max }$ has been chosen since it depends deeply on VGT stator blades position (i.e. VGT opening) and therefore it gives a good estimation of how big is flow distortion due to stator wakes i.e. a low vorticity flow will give a better $\eta_{V G T \text {,max }}$. On the contrary, heat will follow the opposite way, i.e. a good $\eta_{V G T, \text { max }}$ will imply a lower heat transfer due to lower turbulence degree and lower flow incidence on rotor blades. 


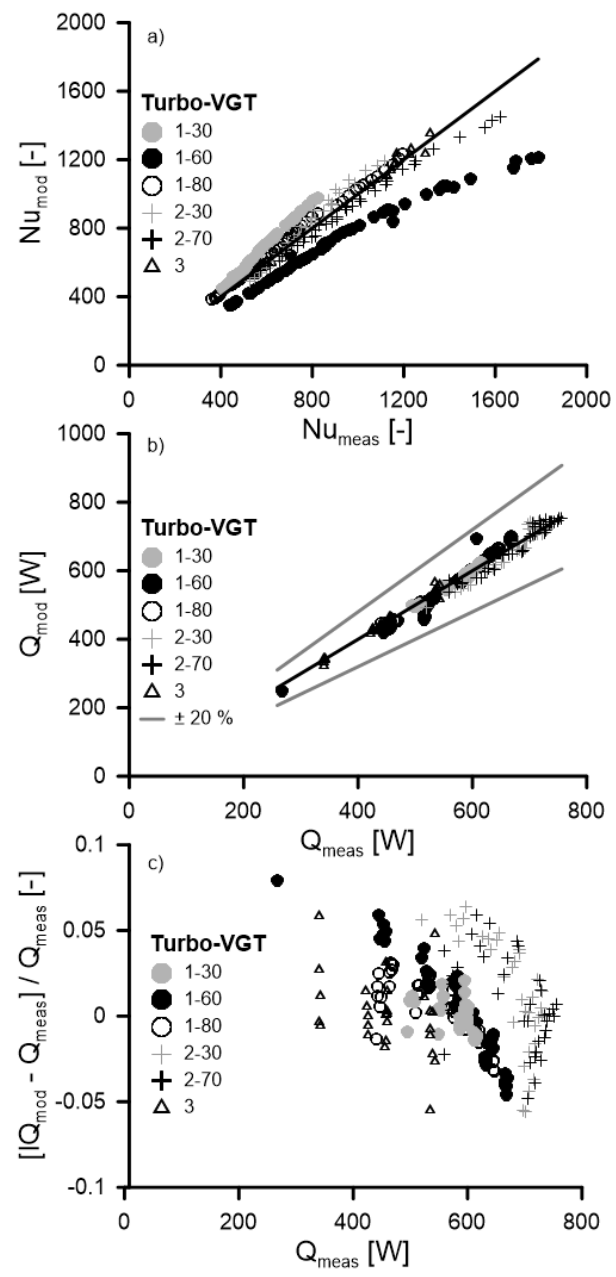

Figure 6: Comparison between model and experimental measurement for Nusselt (top) and heat flux (center) and the difference between measured and modelled heat flux (bottom) from node Gas to node T. Legends refer to turbocharger number and VGT opening in \%

\subsection{Compressor heat transfer coefficients}

In the compressor side, heat transfer from its case to the air inside the diffuser can be calculated, according to the proposed lumped model (Figure 3(b) using Equation 14. It has been assumed that there are no heat losses to the ambient through the insulated turbocharger. 


$$
\dot{Q}_{C / A i r}=\dot{Q}_{H 3 / C}=K_{H 3 / C} \cdot\left(T_{H 3}-T_{C}\right)
$$

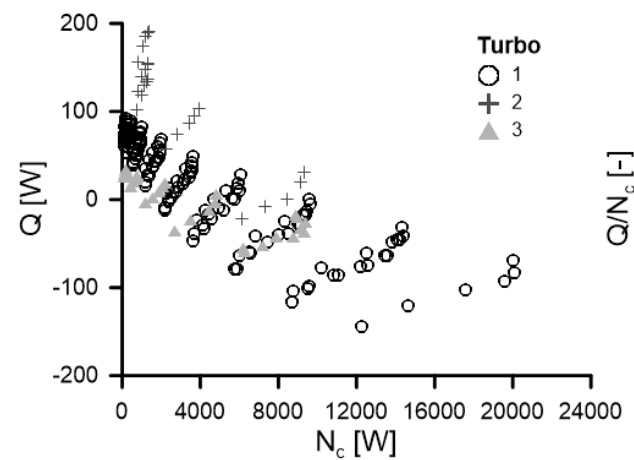
air, heat can flow in two different directions:

In normal operative conditions, i.e. hot turbine gases and cold compressor

1. Compressed air absorbs energy from metal node $C$ (representing compressor case) leading to positive values of $\dot{Q}_{C / \text { Air }}$ ). That situation occurs from medium to low power as it is observed in Figure 7 that corresponds to medium/low loads at engine operation, these are operative conditions representative of urban driving in passenger cars. In those conditions, lubricating oil will be hotter than compressed air and heat transfer mechanism will move to increase compressor outlet temperature. Under those conditions, directly determined efficiency (with measured temperatures) will show a lower value compared to the real one [45].

2. On the contrary, when compressor load increases (higher compression ratio and mass flows) compressor outlet temperature will be higher than lubricating oil. In those conditions heat transfer mechanism will be reversed, i.e. heat will flow from node $C$ to $H_{3}$ represented as negative fluxes in Figure 7. Hence, obtained compressor efficiency using measured temperatures will be higher than real isentropic efficiency [45].

Figure 7: Importance of heat flux $\dot{Q}_{C / A i r}$. Left: absolute value, Right: relative importance compared to compressor enthalpy drop. 
Measured heat fluxes indicated that previous assumption (considering heat flux at compressor diffuser after adiabatic compression) was closer to reality than the assumptions considering heat flux at compressor inlet [9. In this case, heat could not flow from compressor inlet to central housing due to its lower temperature. That fact is clearly observed in Figure 8, where measured heat flux has been represented against two different measured temperature drops. On the one hand, temperature difference between compressor casing temperature and compressor inlet temperature $\left(\Delta T_{C-I C}\right)$. On the other hand, temperature difference between compressor casing and compressor outlet temperatures $\left(\Delta T_{C-O C}\right)$. As it is observed, chart a) of Figure 8 has no sense. Since heat transfer flux reduces when the temperature drop increases and it changes in direction (negative value) for even higher temperature drops. Figure 8,b) shows the best results since negative heat fluxes only appear for negative temperature drops (defined as $\Delta T_{C-O C}$ ) and positive heat fluxes appear for positive temperature drops. In addition a monotonically increasing trend is observed what agrees with higher heat fluxes for higher temperature drops.
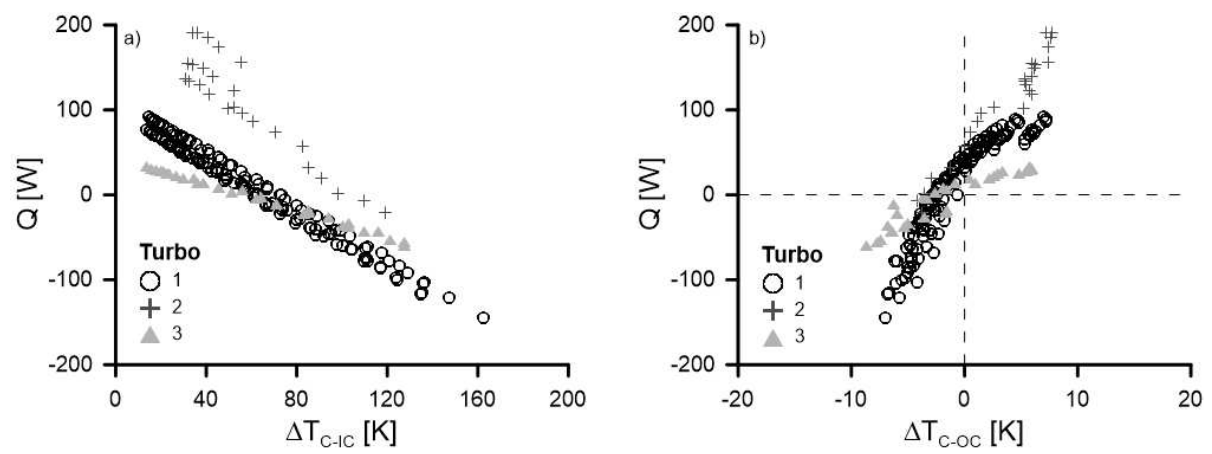

Figure 8: Measured $\dot{Q}_{C / A i r}$ heat flux versus difference of temperature between compressor casing temperature and compressor air temperature. Left: compressor inlet, Right: compressor outlet.

326 The definition of the dimensionless numbers on the compressor are as follows

$$
\operatorname{Re}_{m C}=\frac{4 \cdot \dot{m}_{C}}{\pi \cdot \mu \cdot D_{C O D}}
$$


Where diameter at compressor outlet duct $\left(D_{C O D}\right)$, has been chosen as the characteristic diameter for both the Reynolds and Nusselt numbers.

Proposed correlation for Nusselt number governing heat transfer phenomena from node $C$ to node Air will be similar to the Dittus-Boelter correlation. Constants and Prandtl number exponent for that expression will depend whether the air heats or cools according to the temperatures from neighbouring nodes as Equation 16 shows.

$$
\overline{\mathrm{Nu}_{C / A}}=\left\{\begin{array}{ccc}
0.284 \cdot \mathrm{Re}_{m C}^{0.8} \cdot \operatorname{Pr}^{0.3} & \text { if } & \mathrm{T}_{\text {air }}<\mathrm{T}_{\text {wall }}(Q>0) \\
0.095 \cdot \mathrm{Re}_{m C}^{0.8} \cdot \operatorname{Pr}^{0.4} & \text { if } & \mathrm{T}_{\text {air }}>\mathrm{T}_{\text {wall }}(Q<0)
\end{array}\right\}
$$

Heat transfer will be modelled using Equation 16 for the Nusselt number and an average temperature for the air. The average temperature for the air is calculated between compressor adiabatic outlet temperature $\left(T_{\text {Air }}\right.$ in Figure 3(b) and compressor outlet temperature $\left(T_{O C}\right.$ in Figure 3(b) (as Equation 17 shows. In Equation $17 L_{\text {eff }}$ has been chosen as compressor external case diameter.

$$
\dot{Q}_{C / A}=\overline{\mathrm{Nu}_{C / A}} \cdot \kappa \cdot \pi \cdot L_{e f f} \cdot\left(T_{C}-\frac{T_{O C}+T_{A i r}}{2}\right)
$$

Validation of the proposed correlation is presented in Figure 9 , where differences observed between modelled heat flux and measured values are observed for the three studied turbochargers. Boundary lines in 9 shows $\pm 20 \%$ error as usual.

\subsection{Cooling media heat transfer coefficients}

In case of a water cooled turbocharger (as the named as first and third in Table 2p, an extra convective branch is needed in order to take account for the water coolant. This branch is shown in Figure $3(\mathrm{~b})$ in dashed line linking $\mathrm{H}_{2}$ and $W$ nodes. This circuit works as an energy sink and so heat flux recovered by node $W$ can be directly determined as the enthalpy drop through the coolant circuit as Equation 18 shows. 


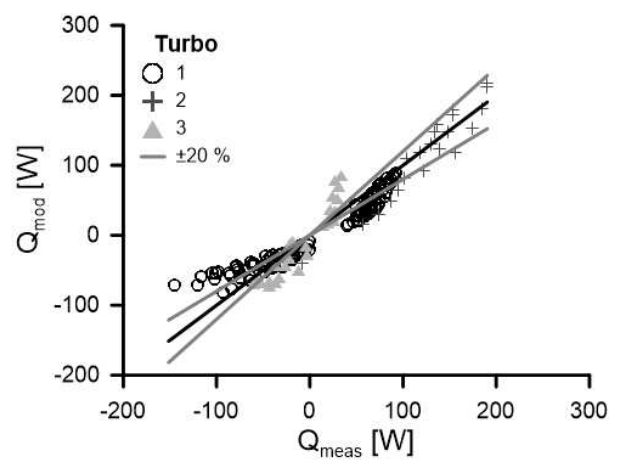

Figure 9: Comparison between model and experimental measurement for heat flux from node $C$ to node $A$

$$
\dot{Q}_{H 2 / W}=\dot{m} \cdot c_{p} \cdot \Delta T_{W}
$$

Importance of this heat flow is shown in Figure 10 where, for low load conditions, heat removed by cooling port can reach $40 \%$ of turbine gas enthalpy drop. Comparing Figures 4 and 10 , both fluxes $\left(\dot{Q}_{T / \text { Gas }}\right.$ and $\left.\dot{Q}_{H 2 / W}\right)$ are similar in magnitude compared to turbine enthalpy drop, i.e. the coolant media act as an efficient thermal insulation between turbine and compressor. That effect will be also observed in oil branches (next section 4.4), in case of cooled turbochargers the heat recovered by lubricating oil drastically reduces compared with non-cooled turbochargers.

Obtained Nusselt number correlation (Equation 19) in that branch is similar to the Dittus-Boelter correlation [21] where the port diameter and housing length have been used as the scale diameter and the effective length respectively. Cooling liquid properties (Prandtl number, viscosity and specific heat at constant pressure) will be estimated at inlet conditions.

$$
N u_{H 2 / W}=0.096 \cdot \operatorname{Re}_{D}^{0.8} \cdot \operatorname{Pr}^{0.4}
$$

Validation of proposed correlation to model heat transfer from node $H_{2}$ to node $W$ is shown in Figure 11, where the $\pm 20 \%$ boundary lines are shown. 

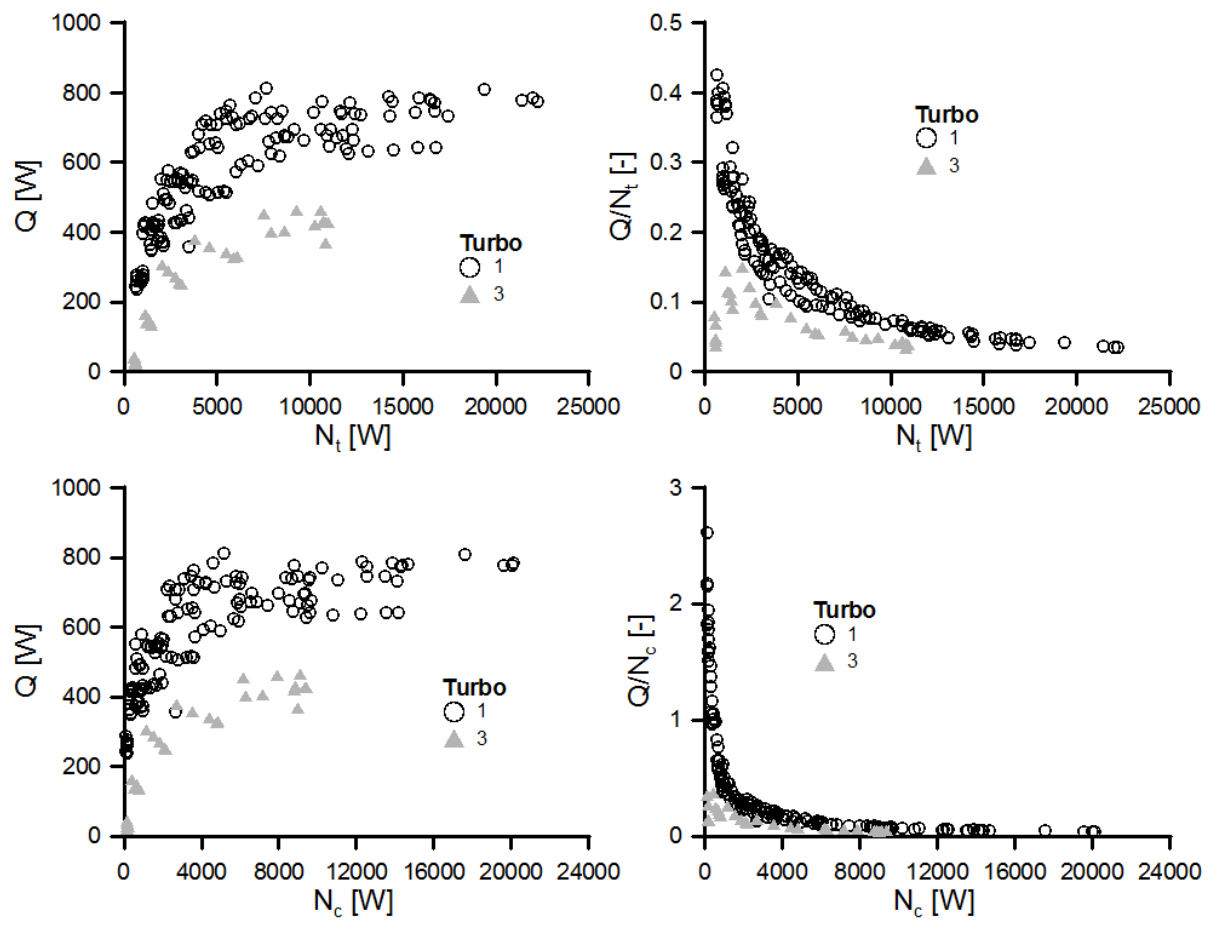

Figure 10: Importance of heat flux $\dot{Q}_{H 2 / W}$. Left: absolute value, Right: relative importance. Top: compared to turbine enthalpy drop and bottom compared to compressor enthalpy drop

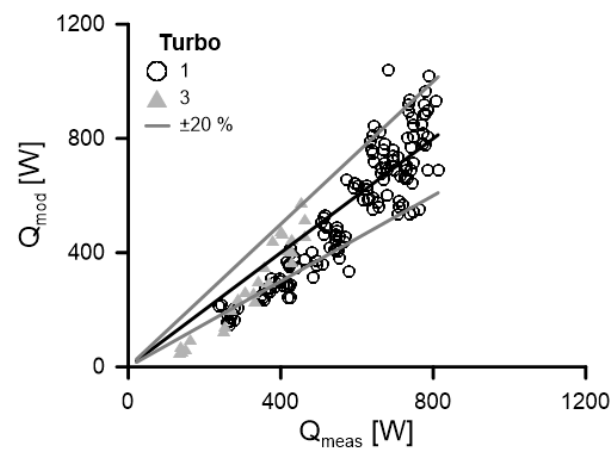

Figure 11: Heat fluxes modelling from node $H_{2}$ to node $W$ 


\subsection{Oil heat transfer coefficients}

Heat transfer from the central housing to the lube oil can be very important depending on turbocharger operating conditions and if the turbocharger is water-cooled or not. In case of water-cooled turbochargers most of the heat will be absorbed by the coolant and, therefore, oil will be heated mainly by mechanical losses. That is due, among other factors, by the higher heat capacity of the coolant. In the case of no water-cooled turbochargers, lubricating oil will act as the heat sink, making a similar role than the coolant. These heat fluxes are calculated from the metal nodes temperature measurement and using previously known metal conductances (Equation 20) according to proposed lumped model:

$$
\begin{array}{r}
\dot{Q}_{H 2 / O i l}=\dot{Q}_{H 1 / H 2}-\dot{Q}_{H 2 / H 3}= \\
=K_{H 1 / H 2} \cdot\left(T_{H 1}-T_{H 2}\right)-K_{H 2 / H 3} \cdot\left(T_{H 2}-T_{H 3}\right)
\end{array}
$$

In case of a water-cooled turbocharger, the energy balance at central node $\left(H_{2}\right)$ is expressed in Equation 21 and it includes the heat flux transmitted to the cooling liquid $\left(\dot{Q}_{H 2 / W}\right)$, which is calculated as in Equation 18

$$
\dot{Q}_{H 2 / O i l}=\dot{Q}_{H 1 / H 2}-\dot{Q}_{H 2 / H 3}-\dot{Q}_{H 2 / W}
$$

Relative importance of that flux $\left(\dot{Q}_{H 2 / O i l}\right)$ is shown in Figure 12 where two different behaviors have been observed:

- In the case of non-water cooled turbocharger (turbo 2): this heat flow can be as high as $18 \%$ of turbine enthalpy drop at low loads; while reducing to almost a $5 \%$ of this drop at high loads.

- In the case of water-cooled turbochargers (turbos 1 and 3): this heat flow compared to turbine or compressor enthalpy drops is lower than for turbo 2 , except for the really low powers where differences are not so clear. 
Nusselt number correlation has been chosen in the original fashion of Sieder-

388 Tate expression, but with different fitting constant (as Equation 22 shows). Oil port diameter has been used for the scale length of Reynolds' number calculation

$390\left(D_{e f f}\right)$. Meanwhile housing external diameter has been chosen as characteristic 391 length $\left(L_{\text {eff }}\right)$.

$$
\overline{\mathrm{Nu}_{H 2 / O i l}}=2.51 \cdot \operatorname{Re}_{m O}^{0.8} \cdot \operatorname{Pr}^{0.3} \cdot\left(\frac{\mu}{\mu_{p}}\right)^{0.14}
$$



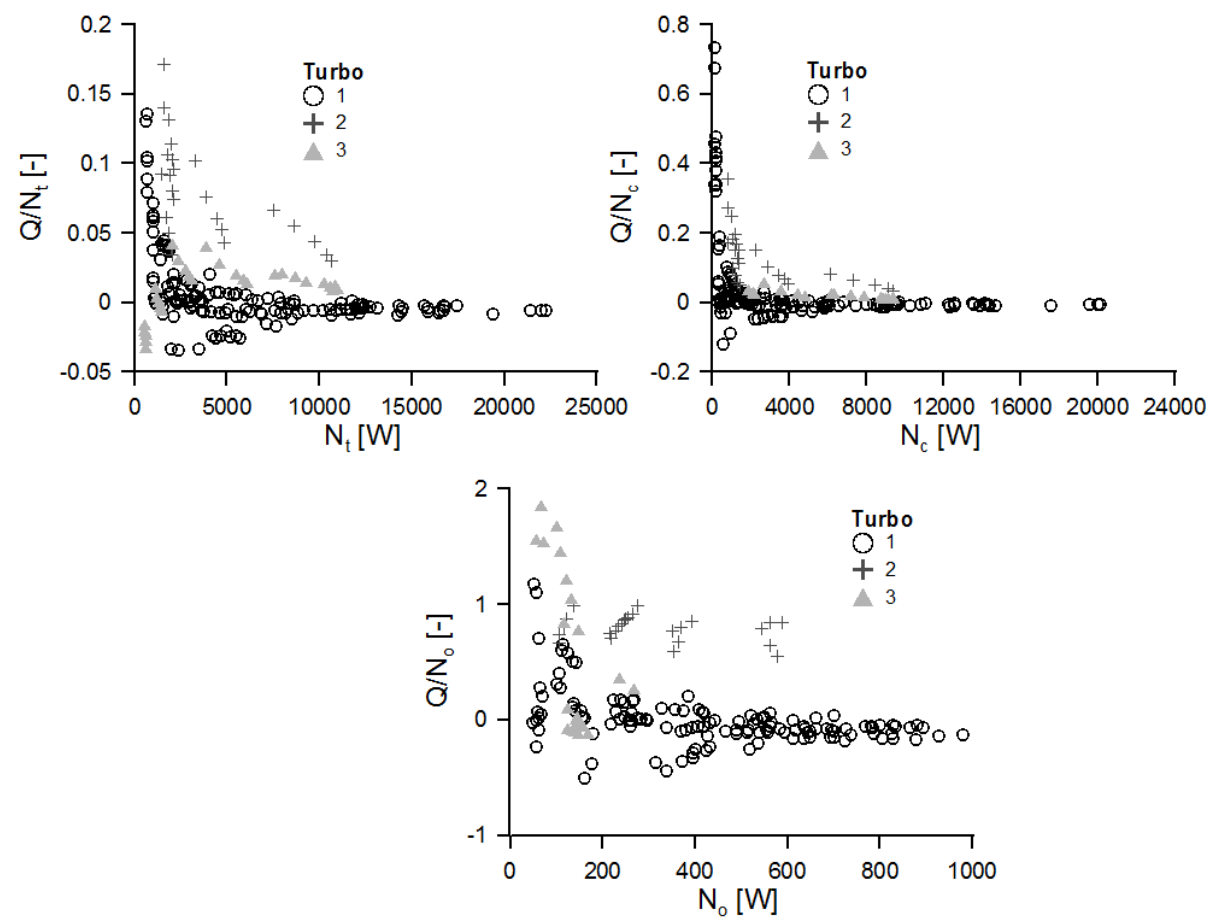

Figure 12: Importance of heat flux $\dot{Q}_{H 2 / O i l}$. Left: relative importance compared to turbine enthalpy drop. Right: relative importance compared to compressor enthalpy drop, Bottom: relative importance compared to oil enthalpy drop

Finally, heat fluxes effects from node $H_{2}$ to node $O i l$ have been evaluated as sketched in Figure 13 i.e. once oil temperature increases, due to mechanical friction losses, up to conditions named $O O / H 2$ in Figure 13 Equation 23 express how oil exchanges heat with central housing node $H_{2}$ and from the average temperature between oil outlet $(O O)$ and $O O / H 2$ (see Figure 13 for nomenclature ). Figure 14 shows the agreement modelling heat fluxes between node $\mathrm{H}_{2}$ and $\mathrm{Oil}$, being visible the $\pm 20 \%$ reference error lines.

$$
\dot{Q}_{H 2 / O i l}=\overline{\mathrm{Nu}_{H 2 / O i l}} \cdot \kappa \cdot \pi \cdot L_{e f f} \cdot\left(T_{H 2}-\frac{T_{O O}+T_{O O / H 2}}{2}\right)
$$




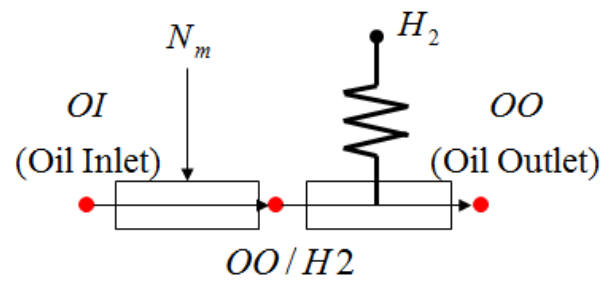

Figure 13: Heat flux paths to oil

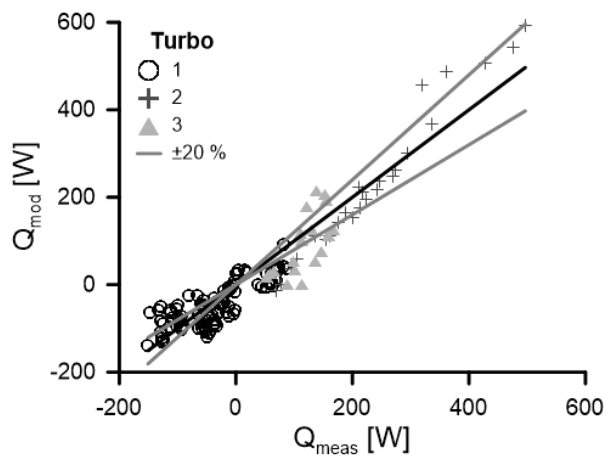

Figure 14: Comparison between model and experimental measurement for heat flux from node H2 to node oil 


\section{Model application}

The validation of the proposed model is performed by comparing model results with experimental measurements in fluids outlet temperature (turbine, compressor, oil and coolant) for Turbocharger number 1. Besides, simulation of these temperatures without using the model are also presented in order to show the improvements in their estimation (Figure 15 ), where the main advantages are following depicted:

- In the prediction of turbine outlet temperature a clear advantage of using the proposed correlations is observed (top of Figure 15), where: if no Heat Transfer model is used (w/o HT) an overestimation of this temperature up to $30{ }^{\circ} \mathrm{C}$ is plotted, while when using the model, the error falls into a very narrow range $\left( \pm 10^{\circ} \mathrm{C}\right)$. This temperature is a very relevant magnitude if two stage turbocharging, exhaust energy recovering or aftertreatment systems are desired to be properly modelled.

- An improvement in compressor outlet temperature is also observed in Figure 15 but, in this case, the highest improvement is observed at low turbocharger loads (i.e. low measured $T_{O C}$ ) since at higher loads, compressor behaves almost adiabatically and, hence, the heat transfer effect is low as explained in section 4.2

- Finally, another non-negligible advantage is the analysis capabilities gained thanks to the prediction of both oil and coolant outlet temperatures which can not be predicted without a Heat Transfer Model. The difference between predicted and measured oil outlet temperatures $\left(T_{O O}\right)$ are shown in Figure 15 where only a $\pm 4{ }^{\circ} \mathrm{C}$ of maximum deviation is observed but the majority of the points are in a narrow range $\left( \pm 2{ }^{\circ} \mathrm{C}\right)$. In the case of coolant outlet temperatures $\left(T_{O W}\right)$, a deviation of $\pm 1{ }^{\circ} \mathrm{C}$ is observed.

The generality of the obtained correlations are demonstrated since they have been used for analysing the performance of different turbochargers measured in 


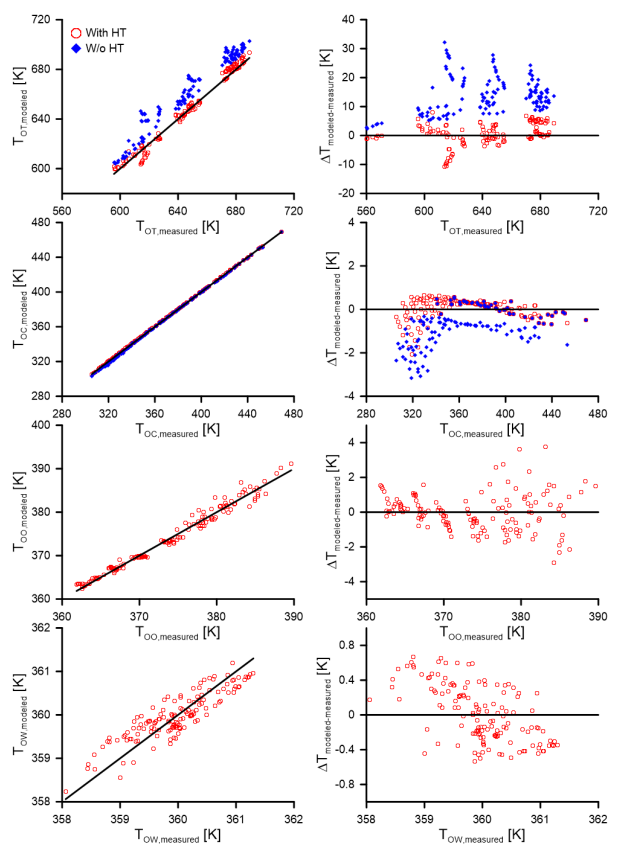

Figure 15: Comparison between model results and experimental data for outlet fluid temperatures. Up to down: turbine, compressor, oil and coolant. Left: absolute value, Right: difference between model results and experimental values. 
turbocharger test rig [36], measured in engine conditions by a different automotive manufacturer [46, they have been checked for other laboratories and in different operation conditions and on different engine (petrol) and with a quite different turbocharger 47]

\section{Conclusions}

Traditionally, heat losses in small turbochargers have been neglected and the behaviour of the machine has been predicted by direct use of manufacturer maps with a look-up table approach. But at low loads, that energy transfer can reach values even higher than turbocharger mechanical power.

This work presents a concise methodology to measure and model these heat fluxes by means of a simplified lumped model. Measurement analysis of main convective heat transfer coefficients has been performed. These have showed:

- Heat losses in turbine side grow with turbine enthalpy drop, but relative to it has a high influence only at low loads.

- Similar behaviour has been observed at compressor side, where adiabatic behaviour can be considered at medium - high loads, since in those points relative importance of heat transfer is almost negligible, due, among others, to the low residence time of the fluid.

- Heat transfer in compressor side should be concentrated at compressor outlet since non of heat should arrive to compressor inlet.

- No problems have been observed when using the assumption of concentrating all heat transfer from the turbine at turbine inlet (turbine casing) and to avoid considering heat transfer through turbocharger shaft.

With the performed measurements, the different convective coefficients have been fitted to general expressions of Nusselt numbers. Finally, the use of these correlations in order to obtain the different fluid outlet temperatures have shown a clear improvement (of almost $20^{\circ} \mathrm{C}$ ) in turbine outlet temperature prediction 
compared with the prediction obtained without heat transfer model. In the case of compressor outlet temperature the maximum deviation observed with proposed model with respect to performed measurements is $2{ }^{\circ} \mathrm{C}$, while in oil outlet temperature and coolant outlet temperature the most of the modelled points fall into the range of $\pm 2{ }^{\circ} \mathrm{C}$ and $\pm 1{ }^{\circ} \mathrm{C}$ respectively with respect to measured temperatures.

\section{Acknowledgments}

This work has been partially supported by the Spanish Ministerio de Economa y Competitividad through grant no. TRA2012-36954. The equipment used in this work has been partially supported by FEDER project funds "Dotación de infraestructuras científico técnicas para el Centro Integral de Mejora Energética y Medioambiental de Sistemas de Transporte (CiMeT), (FEDER-ICTS-201206)", framed in the operational program of unique scientific and technical infrastructure of the Ministry of Science and Innovation of Spain.

\section{References}

[1] S. Jaichandar, K. Annamalai, Combined impact of injection pressure and combustion chamber geometry on the performance of a biodiesel fueled diesel engine, Energy 55 (2013) 330 - 339.

[2] A. J. Torregrosa, A. Broatch, R. Novella, L. F. Mónico, Suitability analysis of advanced diesel combustion concepts for emissions and noise control, Energy 36 (2011) $825-838$.

[3] I. Al-Hinti, M. Samhouri, A. Al-Ghandoor, A. Sakhrieh, The effect of boost pressure on the performance characteristics of a diesel engine: A neuro-fuzzy approach., Applied Energy 86 (2009) 113-121.

[4] J. R. Serrano, F. J. Arnau, V. Dolz, A. Tiseira, M. Lejeune, N. Auffret, Analysis of the capabilities of a two-stage turbocharging system to fulfil the 
US2007 anti-pollution directive for heavy duty diesel engines, International Journal of Automotive Technology 9 (2008) 277-288.

[5] V. Bermúdez, J. M. Luján, B. Plá, W. G. Linares, Effects of low pressure exhaust gas recirculation on regulated and unregulated gaseous emissions during nedc in a light-duty diesel engine, Energy 36 (2011) 5655 - 5665.

[6] M. Jia, Y. Li, M. Xie, T. Wang, Numerical evaluation of the potential of late intake valve closing strategy for diesel $\{\mathrm{PCCI}\}$ (premixed charge compression ignition) engine in a wide speed and load range, Energy 51 (2013) $203-215$.

[7] B. Prasad, C. Sharma, T. Anand, R. Ravikrishna, High swirl-inducing piston bowls in small diesel engines for emission reduction, Applied Energy 88 (2011) $2355-2367$.

[8] B. Kegl, Influence of biodiesel on engine combustion and emission characteristics, Applied Energy 88 (2011) 1803-1812.

[9] S. Shaaban, Experimental Investigation and Extended Simulation of Turbocharger Non-Adiabatic Performance, Ph.D. thesis, Universitat Hannover, Fachbereich Maschinenbau, 2004.

[10] J. R. Serrano, P. Olmeda, F. J. Arnau, M. A. Reyes-Belmonte, A. Lefebvre, Importance of heat transfer phenomena in small turbochargers for passenger car applications, SAE Int. J. Engines 6 (2013) 2013-01-0576.

[11] J. R. Serrano, P. Olmeda, A. Tiseira, L. M. García-Cuevas, A. Lefebvre, Theoretical and experimental study of mechanical losses in automotive turbochargers, Energy 55 (2013) 888-898.

[12] D. Bohn, N. Moritz, M. Wolff, Conjugate Flow and Heat Transfer Investigation of a Turbo Charger: Part II - Experimental Results, in: Proceedings of ASME Turbo Expo, volume 3, ASME, 2003, pp. 723-729. 
[13] D. Bohn, T. Heuer, K. Kusterer, Conjugate Flow and Heat Transfer Investigation of a Turbocharger. Part I: Numerical Results, in: Proceedings of ASME Turbo Expo, volume 3, ASME, 2003, pp. 715-722. Atlanta, Georgia, USA, June 1619, 2003 ISBN: 0-7918-3686-X — eISBN: 0-7918-3671-1.

[14] M. V. Casey, T. M. Fesich, The efficiency of turbocharger compressors with diabatic flows, Journal of Engineering for gas turbines and powerTransactions of the ASME 132 (2010) 072302.

[15] S. Shaaban, J. Seume, Impact of turbocharger non-adiabatic operation on engine volumetric efficiency and turbo lag, International Journal of Rotating Machinery 2012 (2012) 625453 (11 pages).

[16] N. Baines, K. D. Wygant, A. Dris, The analysis of heat transfer in automotive turbochargers, Journal of Engineering for Gas Turbines and Power - Transactions of the ASME 132 (2010) 42301.

[17] M. Cormerais, J. Hetet, P. Chessé, A. Malboom, Heat Transfers Characterization in a Variable Geometry Turbocharger: Experiments and Correlations, in: Proceedings of the 2006 Spring Technical Conference of the ASME Internal Combustion Engine Division, ASME, 2006, pp. 53-64.

[18] M. Cormerais, P. Chessé, J. Hetet, Turbocharger heat transfer modeling under steady and transient conditions, Int. J. of Thermodynamics 12 (4) (2009) 193-202.

[19] P. Chessé, D. Chalet, X. Tauzia, Impact of the Heat Transfer on the Performance Calculations of Automotive Turbocharger Compressor, Oil and Gas Science and technology - Revue D IFP Energier nouvelles 66 (2011) 791-800.

[20] A. Romagnoli, R. Martínez-Botas, Heat transfer analysis in a turbocharger turbine: An experimental and computational evaluation, Applied Thermal Engineering 38 (2012) 58-77. 
[21] F. Dittus, L. Boelter, Heat transfer in automobile radiators of the tubular type, University of California Publications in Engineering 2 (1930) 443-461.

[22] H. Aghaali, H.-E. Ångstrom, Turbocharged SI-engine simulation with cold and hot-measured turbocharger performance maps, in: Proceeding of ASME Turbo Expo, pp. GT2012-68758.

[23] R. Burke, C. Vagg, D. Chalet, P. Chesse, Heat transfer in turbocharger turbines under steady, pulsating and transient conditions, International Journal of Heat and Fluid Flow 52 (2015) 185 - 197.

[24] S. Lavagnoli, C. D. Maesschalck, G. Paniagua, Uncertainty analysis of adiabatic wall temperature measurements inturbine experiments, Applied Thermal Engineering 82 (2015) 170 - 181.

[25] Society of Automotive Engineers, Supercharger testing standard, SAE SAE J1723 (1995).

[26] Society of Automotive Engineers Inc, Turbocharger gas stand test code, SAE SAE J1826 (1995).

[27] J. R. Serrano, P. Olmeda, A. Tiseira, L. M. García-Cuevas, A. Lefebvre, Importance of mechanical losses modelling in the performance prediction of radial turbochargers under pulsating flow conditions, SAE Int. J. Engines 6 (2013) 2013-01-0576.

[28] F. Payri, J. R. Serrano, P. Olmeda, A. Páez, F. Vidal, Experimental Methodology to Characterize Mechanical Losses in Small Turbochargers, in: Proceedings of the ASME Turbo Expo 2010, volume 5, pp. 413-424.

[29] JCGM 100:2008, Evaluation of measurement data - Guide to the expression of uncertainty in measurement, BIPM, 2008.

[30] D. Kulkarni, G. Rupertus, E. Chen, Experimental investigation of contact resistance for water cooled jacket for electric motors and generators, IEEE Transactions on Energy Conversion 27(1) (2002) 204-210. 
[31] R. Wrobel, G. Vainel, C. Copeland, T. Duda, D. Staton, P. Mellor, Investigation of mechanical loss and heat transfer in an axial-flux pm machine, in: Energy Conversion Congress and Exposition (ECCE), 2013 IEEE, pp. $4372-4379$.

[32] J. R. Serrano, P. Olmeda, A. Páez, F. Vidal, An experimental procedure to determine heat transfer properties of turbochargers, Measurement Science and Technology 21 (2010) 035109 (14pp).

[33] F. Bet, G. Seider, Thermal management of a turbocharger for unsteady operation, in: STAR European Conference.

[34] F. P. Incropera, D. P. Dewitt, T. L. Bergman, A. S. Lavine, Fundamentals of Heat and Mass Transfer, John Wiley \& Sons, Inc., 111 River Street, Hoboken, NJ 0703-5774, 6th edition, 2007.

[35] J. R. Serrano, P. Olmeda, F. J. Arnau, A. Dombrovsky, General procedure for the determination of heat transfer properties in small automotive turbochargers, SAE Int. J. Engines 8 (1) (2015) 30-41.

[36] J. R. Serrano, P. Olmeda, F. J. Arnau, A. Dombrovsky, S. L., Analysis and methodology to characterize heat transfer phenomena in automotive turbochargers, ASME. J. Eng. Gas Turbines Power 137 (2014) 021901021901-11.

[37] L. Weili, Z. Yu, C. Yuhong, Calculation and analysis of heat transfer coefficients and temperature fields of air-cooled large hydro-generator rotor excitation windings, IEEE TRANSACTIONS ON ENERGY CONVERSION 26 (3) (2011) 946-952.

[38] A. Romagnoli, R. Martínez-Botas, Heat transfer on a turbocharger under constant load points, in: Proceedings of ASME Turbo Expo, volume 5, pp. 163-174.

[39] D. Hagelstein, B. Beyer, J. Seume, M. Rautenberg, Heuristical view on the non-adiabatic coupling system of combustion engine and turbocharger, 
in: Proceedings of the 7th International Conference on Turbochargers and Turbocharging,, p. C602/015.

[40] S. Thorpe, S. Yoshino, R. Ainsworth, N. Harvey, An investigation of the heat transfer and static pressure on the over-tip casing wall of an axial turbine operating at engine representative flow conditions. (i). time-mean results, International Journal of Heat and Fluid Flow 25(6) (2004) 933-944.

[41] S. Lavagnoli, G. Paniagua, C. De Maesschalck, T. Yasa, Analysis of the unsteady overtip casing heat transfer in a high speed turbine, Journal of turbomachinery - transactions of the ASME 135 (2013) 031027.

[42] C. D. Maesschalck, S. Lavagnoli, G. Paniagua, N. Vinha, Aerothermodynamics of tight rotor tip clearance flows in high-speed unshrouded turbines, Applied Thermal Engineering 65 (2014) 343 - 351.

[43] D. Kraft, A Software Package for Sequential Quadratic Programming, Forschungsbericht // Deutsche Forschungs- und Versuchsanstalt für Luftund Raumfahrt, DFVLR, 1988.

[44] F. Payri, J. R. Serrano, P. Fajardo, M. A. Reyes-Belmonte, R. GonzaloBelles, A physically based methodology to extrapolate performance maps of radial turbines', Energy Conversion and Management 55 (2012) 149-163.

[45] J. R. Serrano, P. Olmeda, F. J. Arnau, A. Dombrovsky, L. Smith, Methodology to characterize heat transfer phenomena in small automotive turbochargers: experiments and modelling based analysis. gt2014-25179., in: ASME Turbo Expo 2014: Turbine Technical Conference and Exposition.

[46] J. R. Serrano, P. Olmeda, F. J. Arnau, A. Dombrovsky, L. Smith, Turbocharger heat transfer and mechanical losses influence in predicting engines performance by using one-dimensional simulation codes, Energy 86 (2015) 204-218.

[47] A. Rinaldi, H. Tartoussi, S. Guilain, J. R. Serrano, Optimized matching process for gasoline engines for eu6c/eu7, in: SIA Powertrain - Versailles. 